\title{
INVESTIGATIONS OF MECHANICAL PROPERTIES OF API P110 STEEL CASING TUBES OPERATED IN DEEP-SEA SOUR CONDENSATE WELL CONDITIONS
}

\author{
Yao Zilin ${ }^{1}$ \\ Wang Yu ${ }^{2}$ \\ Yang Xuefeng ${ }^{3}$ \\ Gao Anping ${ }^{4}$ \\ Zhang Rong ${ }^{5}$ \\ Jia Yanjie ${ }^{6}$ \\ ${ }^{1}$ College of Chemistry and Chemical Engineering, Southwest Petroleum University, China \\ ${ }^{2}$ Robotics Research Center, School of Mechanical Engineering, China \\ ${ }^{3}$ Heavy Oil Development Company of PetroChina Xinjiang Oilfield Company, China \\ ${ }^{4}$ Wuxi China Resources Gas Co., Ltd, China \\ ${ }^{5}$ Petroleum Engineering School, Southwest Petroleum University, China \\ ${ }^{6}$ Petrochina Southwest Pipeline Company, China
}

\begin{abstract}
Due to the complexity of the marine environment, in deep-sea drilling, all kinds of strings are corroded by different deepsea conditions for a long time, accompanied by high temperature and high pressure, which lead to the continuous change of mechanical properties of materials. In order to solve the problem that the material mechanical parameters cannot be accurately described in the performance analysis of the casing, deep-sea simulated corrosion and material damage experiments of P110 material were carried out in this paper. Mass loss and tensile experiments on corrosion-damaged test pieces were conducted under different corrosion experimental periods. The changes in mechanical properties of the material were analyzed. Equations of the variation of the equivalent yield strength and the equivalent tensile strength were obtained. The results show that the equivalent yield strength and the equivalent tensile strength decrease with the increase of the weight loss rate. Based on the experimental results and finite element analysis, a method for establishing the material corrosion model was proposed in this paper. The deep-sea drilling corrosion performance model of P110 material was established, which greatly reduced the error caused by the material uniformity assumption in finite element analysis. This paper provides a theoretical basis for the analysis of reliability and life of P110 materials in wells.
\end{abstract}

Keywords: deep-sea drilling environment, mechanical properties, yield strength, tensile strength, corrosion modeling

\section{INTRODUCTION}

With the gradual expansion of global offshore oil and gas field development, the damage of downhole strings becomes more and more serious with the increase of the service cycle. Especially in the process of deep-sea drilling, because the deepsea corrosion environment is too complex, the corrosion damage accumulates with the time, resulting in continuous change of the mechanical properties of the casing, resulting in casing damage accidents, resulting in huge economic losses, which brings great difficulties to the oil well exploitation $[1,2,3]$.
In recent years, a large number of studies on casing corrosion of oil and gas wells has been carried out. Regularized treatment of casing corrosion defects with different shapes according to the latest safety assessment standards for pressure vessels with defects is carried out by Zhu et al. [4, 5, 6, 7]. The crushing strength of a casing containing corrosion defects was analyzed by the ANSYS finite element simulation method. Mack et al. studied the indoor evaluation method of casing material selection and analyzed the change in performance of downhole tools due to the corrosive environment during the service period [8]. Chen et al. investigated the effect of alternate 
injection frequency of empty foam liquid on the corrosion of casing steel during high-pressure oil and gas foam flooding $[9,10]$. The aforementioned studies have focused on the effect of the corrosion rate of the casing and the corrosion defects on the residual strength. However, there were few studies on the properties of casing materials after corrosion.

Most research assumes that the material is isotropic, and the material is uniform when using the finite element method for mechanical analysis. This assumption is more reasonable for new materials because the basic requirements for qualified new materials are isotropic, uniform material, and the error can be negligible $[11,12,13]$. However, under complex corrosive conditions, the degree of corrosion is affected by the direction and location of corrosion. Thus, the above assumptions are unreasonable for complex corrosion conditions. Moreover, at present, most of the studies on the performance of casing clothing are focused on land drilling, and there are few studies on deep-sea drilling corrosion.

In this paper, based on deep-sea oil and gas wells, the degree of casing corrosion is directly expressed by the P110 weight loss rate obtained by corrosion damage experiment. A slow strain tensile experiment was performed in the case of casing damage. According to the API value rule, the influence of weight loss rate on the plasticity of the casing is obtained. A dynamic model of the performance of the material under the influence of corrosion is obtained. This paper provides a new idea for the selection of engineering casings and provides a theoretical basis for the life analysis and reliability analysis of casing.

\section{MATERIAL CORROSION EXPERIMENT}

The material and mechanical properties of casings commonly used in oil and gas drilling are shown in Table 1. Due to the high requirements for mechanical properties of materials in deep-sea drilling, P110 material casings are most commonly used in deep-sea drilling. Therefore, P110 material was selected as the research object in this paper, in which carbon accounts for about $3 \%$ and iron accounts for about $50 \%$.

Tab. 1. Mechanical properties of several common casings in API

\begin{tabular}{|c|c|c|c|}
\hline Material & $\begin{array}{c}\text { Yield strength } \\
(\mathrm{MPa})\end{array}$ & $\begin{array}{c}\text { Tensile } \\
\text { strength (MPa) }\end{array}$ & $\begin{array}{c}\text { Maximum } \\
\text { elongation (\%) }\end{array}$ \\
\hline J55 & $379-552$ & $\geq 517$ & 24 \\
\hline K55 & $379-552$ & $\geq 689$ & 20 \\
\hline N80 & $552-758$ & $\geq 689$ & 19 \\
\hline P110 & $758-965$ & $\geq 862$ & 15 \\
\hline
\end{tabular}

The corrosive fluid used in this experiment was the drilling fluid used in deep-sea drilling. Due to the particularity of offshore drilling, it was mixed with sea water according to the proportion in actual production during the experiment.

The main device used in the deep-sea temperature and pressure environment experiment was a self-developed hightemperature autoclave, as shown in Fig. 1. The high-temperature autoclave was used in this experiment. The maximum experimental pressure of the equipment is $70 \mathrm{MPa}$, the maximum experimental temperature is $200^{\circ} \mathrm{C}$, the volume is $5 \mathrm{~L}$, the inner diameter is $150 \mathrm{~mm}$, and the depth is $300 \mathrm{~mm}$.

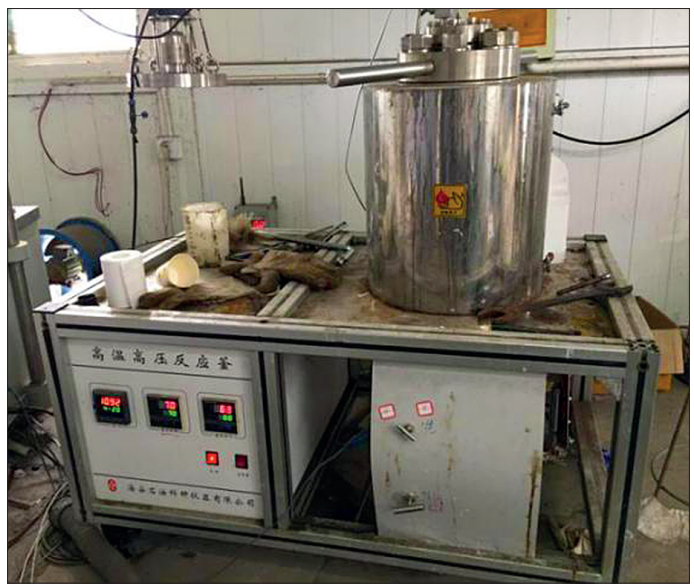

Fig. 1. High-temperature autoclave

The material of this experiment was the casing of ocean oil and gas wells, as shown in Fig. 2. Samples of the casing and tensile test pieces are shown in Figs. 2 and 3. Corrosive liquids were mixed in laboratory tests.

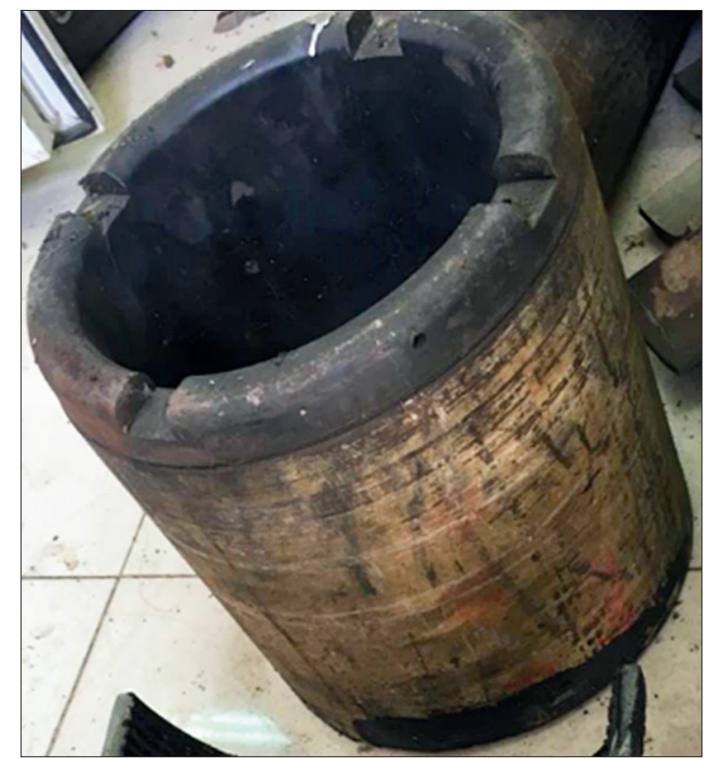

Fig. 2. Before casing sampling

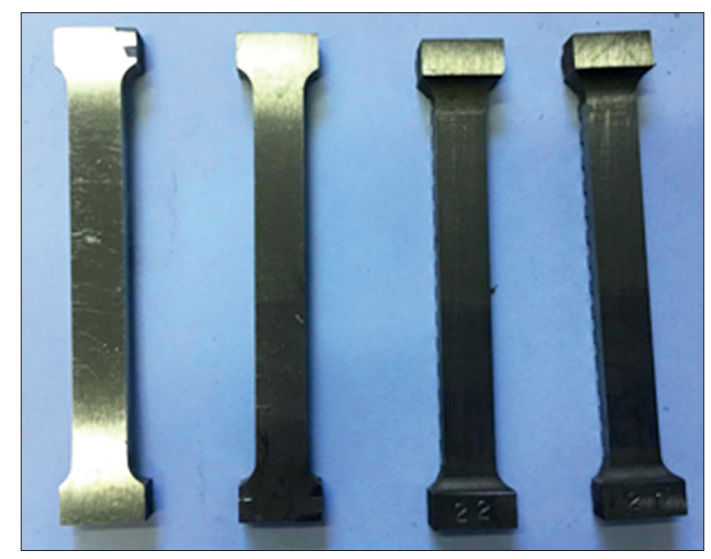

Fig. 3. Tensile test pieces 
Three tensile test pieces were taken for each experiment and polished step-by-step with 240\#, 400\#, 600\#, 800\#, and 1200\# sandpaper, in order to eliminate machined knife marks. The test pieces were cleaned by degreasing with petroleum ether and removing water with alcohol. After drying the test pieces in cold air, they were measured for specific size and weight. Finally, the test pieces were placed in a dry box for use.

At the beginning of the corrosion experiment, the tensile test pieces were hung on a bracket placed in a high-temperature autoclave, and a corrosive liquid was added. Then, a nitrogen gas pressure test was applied to the high-temperature autoclave to ensure the tightness of the autoclave. The oxygen was removed by introducing nitrogen for 2 hours, and the temperature was raised to the design temperature. $\mathrm{CO}_{2}$ and nitrogen were introduced to pressurize to the design pressure. After the experimental time was reached, the operation of the test pieces was finished, and the tensile test pieces were taken out after the pressure was released. The corrosive medium on the surface of the test pieces was removed by liquid for removing the membrane. The method of removing corrosion products was to place the test pieces in a cleaning solution and clean them in an ultrasonic cleaner. The samples were immersed in a saturated sodium bicarbonate solution for about 2 to 3 minutes for neutralization. The samples were rinsed with tap water, blotted with filter paper, and soaked in anhydrous alcohol or acetone for 3 to 5 minutes. The test pieces were dried for a certain period of time to prepare for material damage experiments.

In the first experiment, three of the threaded and unthreaded tensile test pieces were placed in a hightemperature autoclave, the experimental pressure was $10 \mathrm{MPa}$, the experimental temperature was $100^{\circ} \mathrm{C}$, and the experimental period was one week $(168 \mathrm{~h})$. After the end of the experiment, the pressure was released, and the test pieces were taken out until the temperature was lowered to about $60{ }^{\circ} \mathrm{C}$. The tensile test pieces were compared before and after corrosion as shown in Fig. 4.

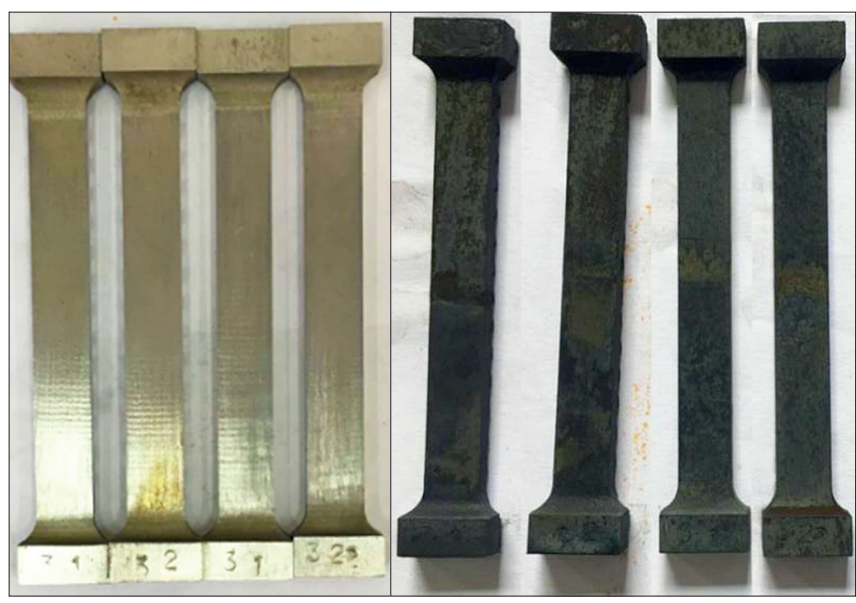

Fig. 4. Comparison of tensile test pieces before and after the experiment

The taken tensile test pieces were washed, air-dried, and weighed, and the weight was compared between before and after the experiment, as shown in Table 2. The three groups of samples were weighed three times respectively, and their values were indicated by serial numbers 1, 2 and 3 .

Tab. 2. Weight before and after the first experiment

\begin{tabular}{|c|c|c|c|c|c|}
\hline \multicolumn{2}{|c|}{ Pre-experiment weight /g } & \multicolumn{3}{c|}{ Post-experiment weight /g } \\
\hline 1 & 2 & 3 & 1 & 2 & 3 \\
\hline 53.871 & 53.739 & 53.815 & 50.089 & 50.071 & 50.081 \\
\hline 53.874 & 53.743 & 53.815 & 50.090 & 50.066 & 50.081 \\
\hline 53.675 & 53.740 & 53.815 & 50.090 & 50.073 & 50.081 \\
\hline
\end{tabular}

The results of the first experiment were analyzed. The weights of the three parallel test pieces before the experiment were $53.807,53.741$, and $53.815 \mathrm{~g}$, respectively. The weights after the experiment were 50.090,50.070, and $50.081 \mathrm{~g}$, respectively. The weight loss rates of the three parallel test pieces were $7.0 \%$, $6.8 \%$, and $6.9 \%$, respectively.

The second experimental temperature and pressure were the same as the first experiment, and the experimental period was $15 \mathrm{~d}(360 \mathrm{~h})$. The tensile test pieces after corrosion were cleaned and air-dried. The three groups of samples were weighed three times respectively, and their values were indicated by serial numbers 4, 5 and 6, as shown in Table 3.

Tab. 3. Weight before and after the second experiment

\begin{tabular}{|c|c|c|c|c|c|}
\hline \multicolumn{3}{|c|}{ Pre-experiment weight /g } & \multicolumn{3}{c|}{ Post-experiment weight /g } \\
\hline 4 & 5 & 6 & 4 & 5 & 6 \\
\hline 34.254 & 34.662 & 34.558 & 29.729 & 30.145 & 30.084 \\
\hline 34.254 & 34.662 & 34.558 & 29.728 & 30.144 & 30.084 \\
\hline 34.255 & 34.663 & 34.558 & 29.728 & 30.145 & 30.084 \\
\hline
\end{tabular}

In the analysis of the results of the second experiment, the average weights of the three unthreaded tensile test pieces before the experiment were $34.254,34.662$, and $34.558 \mathrm{~g}$, respectively. The average weights after the experiment were $29.728,30.145$, and $30.0845 \mathrm{~g}$, respectively. The weight loss rates of the three parallel test pieces were $13.2 \%, 13.0 \%$, and $12.9 \%$, respectively.

The third experimental temperature and pressure were the same as the first experiment, and the experimental period was $12 \mathrm{~d}(288 \mathrm{~h})$. The tensile test pieces after corrosion were cleaned, air-dried, and weighed, using the same method. The results are shown in Table 4.

Tab. 4. Weight before and after the third experiment

\begin{tabular}{|c|c|c|c|c|c|}
\hline \multicolumn{3}{|c|}{ Pre-experiment weight /g } & \multicolumn{3}{c|}{ Post-experiment weight /g } \\
\hline 7 & 8 & 9 & 7 & 8 & 9 \\
\hline 34.095 & 34.867 & 34.547 & 30.644 & 31.188 & 30.893 \\
\hline 34.095 & 34.867 & 34.547 & 30.645 & 31.188 & 30.893 \\
\hline 34.095 & 34.867 & 34.547 & 30.645 & 31.188 & 30.893 \\
\hline
\end{tabular}

In the analysis of the results of the third experiment, the average weights of the three unthreaded tensile test pieces before the experiment were $34.0954,34.8676$, and $34.5472 \mathrm{~g}$, respectively. The average weights after the experiment were 
$30.6451,31.1886$, and $30.8933 \mathrm{~g}$, respectively. The weight loss rates of the three parallel test pieces were $10.1 \%, 10.5 \%$, and $10.6 \%$, respectively.

The experiment was continued in the same way. The experimental pressure was set to $10 \mathrm{MPa}$, and the experimental temperature was $100^{\circ} \mathrm{C}$. Ten groups of samples were taken to change the experimental corrosion time. After the corrosion experiment, the weight data before and after the experiment were measured according to the experimental method described by the above three groups of samples.

A test piece having a severe corrosion pit as shown in Fig. 5 was removed. The test piece, shown in Fig. 6, was taken for washing and weighing, and the results are shown in Table 5.

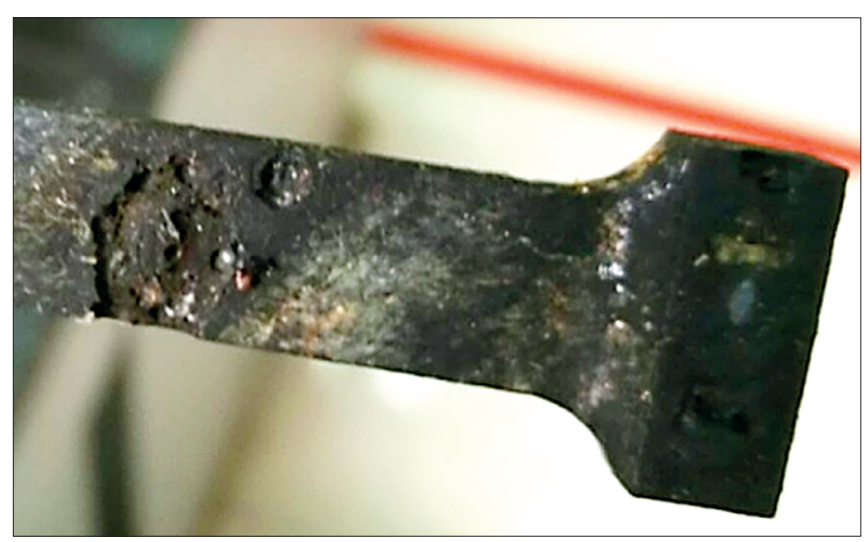

Fig. 5. Severely corroded test piece

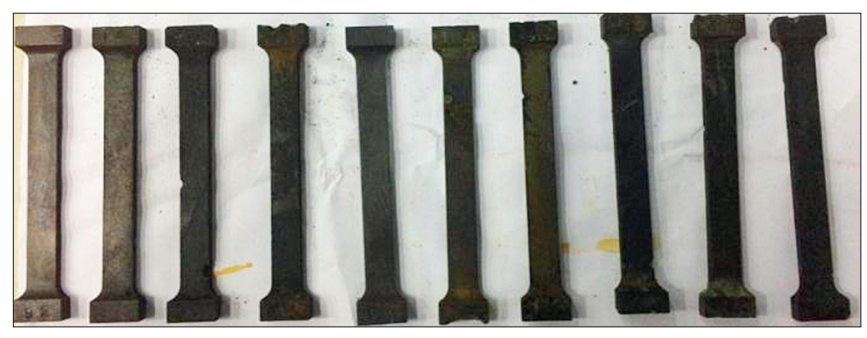

Fig. 6. Selected test pieces

In the corrosion experiments, the degree of corrosion is expressed as the corrosion rate. The corrosion rate is the weight loss in years after the corrosion experiment of the standard test pieces were carried out. In this paper, the degree of corrosion of the material is expressed by the weight loss rate. After the corrosion experiments were completed, the corrosion test pieces were stretched to study the effect of corrosion on the mechanical properties of the material, and the influence law was analyzed.

\section{MATERIAL TENSILE EXPERIMENT}

The material tensile experiment used an MTS hydraulic universal experimenting machine. The servo motor drives the high-precision screw pair to drive the beam up and down to realize the tensile, compression and bending experiments of the test pieces.
Tab. 5. Weight and weight loss rate before and after the experiments

\begin{tabular}{|c|c|c|c|c|}
\hline $\begin{array}{l}\text { Experiment } \\
\text { number }\end{array}$ & Time & $\begin{array}{l}\text { Pre- } \\
\text { experiment } \\
\text { weight }\end{array}$ & $\begin{array}{l}\text { Post- } \\
\text { experiment } \\
\text { weight }\end{array}$ & $\begin{array}{l}\text { Weight loss } \\
\text { rate }\end{array}$ \\
\hline 10 & $300 \mathrm{~h}$ & $34.2148 \mathrm{~g}$ & $30.4956 \mathrm{~g}$ & $10.9 \%$ \\
\hline 11 & $300 \mathrm{~h}$ & $34.1689 \mathrm{~g}$ & $30.3945 \mathrm{~g}$ & $11.0 \%$ \\
\hline 12 & $400 \mathrm{~h}$ & $34.8127 \mathrm{~g}$ & $29.8720 \mathrm{~g}$ & $14.2 \%$ \\
\hline 13 & $450 \mathrm{~h}$ & $33.9654 \mathrm{~g}$ & $28.6941 \mathrm{~g}$ & $15.5 \%$ \\
\hline 14 & $450 \mathrm{~h}$ & $34.5334 \mathrm{~g}$ & $29.1472 \mathrm{~g}$ & $15.6 \%$ \\
\hline 15 & $500 \mathrm{~h}$ & $34.7038 \mathrm{~g}$ & $29.0512 \mathrm{~g}$ & $16.3 \%$ \\
\hline 16 & $550 \mathrm{~h}$ & $33.8899 \mathrm{~g}$ & $27.8835 \mathrm{~g}$ & $17.7 \%$ \\
\hline 17 & $550 \mathrm{~h}$ & $33.7530 \mathrm{~g}$ & $27.7130 \mathrm{~g}$ & $17.9 \%$ \\
\hline 18 & $600 \mathrm{~h}$ & $33.8523 \mathrm{~g}$ & $27.0480 \mathrm{~g}$ & $20.1 \%$ \\
\hline 19 & $700 \mathrm{~h}$ & $34.0259 \mathrm{~g}$ & $25.1792 \mathrm{~g}$ & $26 \%$ \\
\hline
\end{tabular}

Before the experiment, the parallel test pieces were numbered with a steel stamp, the parallel test piece size was measured, and then a tensile experiment was performed. According to the size of the tensile test pieces, two fixtures were fabricated for assisting stretching in this experiment.

Three sets of parallel test pieces were taken in the experiment. The results are shown in Fig. 7. According to the API rule, the average value of the three groups of data was calculated. The yield strength of the new material with no thread was $960 \mathrm{MPa}$, and the tensile strength was $1039 \mathrm{MPa}$. The results satisfy the strength requirements of $\mathrm{P} 110$ steel casing with yield strength range of 758-965 $\mathrm{MPa}$ and tensile strength $\geq 862 \mathrm{MPa}$.

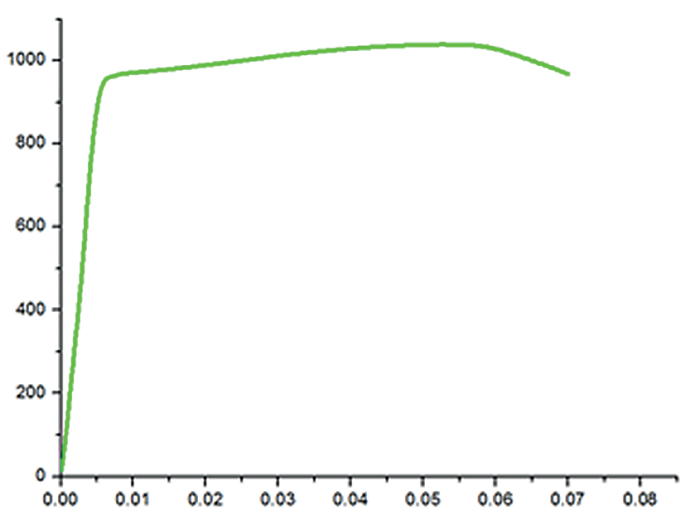

Fig. 7. Stress (X axis)-strain (Y axis) curve of new material without thread 


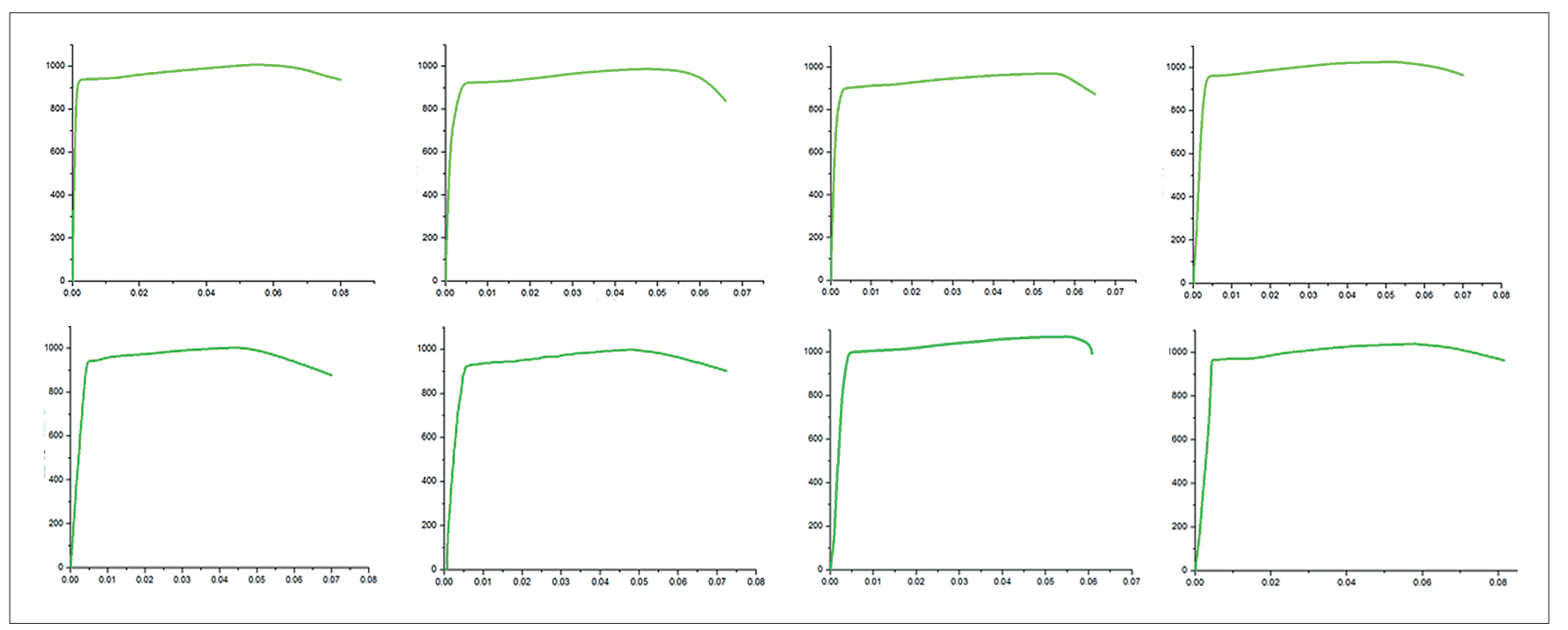

Fig. 8. Stress (X axis)-strain (Y axis) curve after corrosion

After the tensile experiments, the fracture was observed and the tensile data were analyzed. There were at least two normal parallel test pieces for each tensile test piece group. The normal fractured test piece group was selected, as shown in Fig. 8.

\section{DISCUSSION OF EXPERIMENTAL RESULTS}

According to the test results, without considering the influence of corrosion on the area of the test piece, the equivalent yield strength and the equivalent tensile strength of the material after corrosion were calculated by the tensile test data. The mechanical property ratio of the material before and after corrosion was also calculated in Table 6.It can be seen from Table 6 that when the weight loss rate was less than $15 \%$, the equivalent yield strength and the equivalent tensile strength decrease with the increase of the weight loss rate. When the weight loss rate was greater than $15 \%$, the decrease rate of the equivalent yield strength was significantly accelerated, and the equivalent tensile strength was basically unchanged. When the weight loss rate was greater than $20 \%$, the equivalent yield strength of the material was less than $758 \mathrm{MPa}$, which does not meet the requirements for use of the P110 material. According to the data summarized in the table, the equivalent yield strength of all test pieces with weight loss rate less than $20 \%$ in this experiment was calculated, and the curve was fitted to Fig. 9 (left). The equivalent tensile strength of all test pieces with a weight loss rate of less than $15 \%$ in this experiment was calculated, and the curve was fitted to Fig. 9 (right).

In Fig. 9, the green line is the experimental data, the red line is the fitting curve, which are for the change of the equivalent yield strength when the weight loss rate was less than $20 \%$ and the change of the equivalent tensile strength when the weight loss rate was less than $15 \%$, respectively.
Tab. 6. Relationship between weight loss rate and performance parameter changes

\begin{tabular}{|c|c|c|c|c|}
\hline $\begin{array}{l}\text { Weight loss } \\
\text { rate } G_{s}\end{array}$ & $\begin{array}{l}\text { Equivalent } \\
\text { yield } \\
\text { strength }\end{array}$ & $\begin{array}{l}\text { Yield } \\
\text { strength } \\
\text { ratio }\end{array}$ & $\begin{array}{l}\text { Equivalent } \\
\text { tensile } \\
\text { strength }\end{array}$ & $\begin{array}{l}\text { Tensile } \\
\text { strength } \\
\text { ratio }\end{array}$ \\
\hline $6.6 \%$ & 959 & $99.9 \%$ & 1020 & $98.1 \%$ \\
\hline $6.8 \%$ & 956 & $99.6 \%$ & 1010 & $97.1 \%$ \\
\hline $7.0 \%$ & 951 & $99.1 \%$ & 1008 & $96.9 \%$ \\
\hline $10.1 \%$ & 940 & $97.9 \%$ & 998 & $96.0 \%$ \\
\hline $10.5 \%$ & 938 & $97.7 \%$ & 999 & $96.1 \%$ \\
\hline $10.9 \%$ & 930 & $96.7 \%$ & 991 & $95.3 \%$ \\
\hline $11.0 \%$ & 924 & $96.3 \%$ & 988 & $95.0 \%$ \\
\hline $11.3 \%$ & 915 & $95.3 \%$ & 978 & $94.1 \%$ \\
\hline $13.1 \%$ & 887 & $92.4 \%$ & 962 & $92.5 \%$ \\
\hline $13.3 \%$ & 889 & $92.6 \%$ & 965 & $92.8 \%$ \\
\hline $14.2 \%$ & 881 & $91.8 \%$ & 950 & $91.3 \%$ \\
\hline $15.5 \%$ & 879 & $91.6 \%$ & 952 & $91.5 \%$ \\
\hline $16.3 \%$ & 807 & $84.1 \%$ & 957 & $92.0 \%$ \\
\hline $17.9 \%$ & 785 & $81.8 \%$ & 943 & $90.7 \%$ \\
\hline $20.1 \%$ & 751 & $78.3 \%$ & 947 & $91.1 \%$ \\
\hline $20.6 \%$ & 705 & $73.4 \%$ & 953 & $91.6 \%$ \\
\hline
\end{tabular}




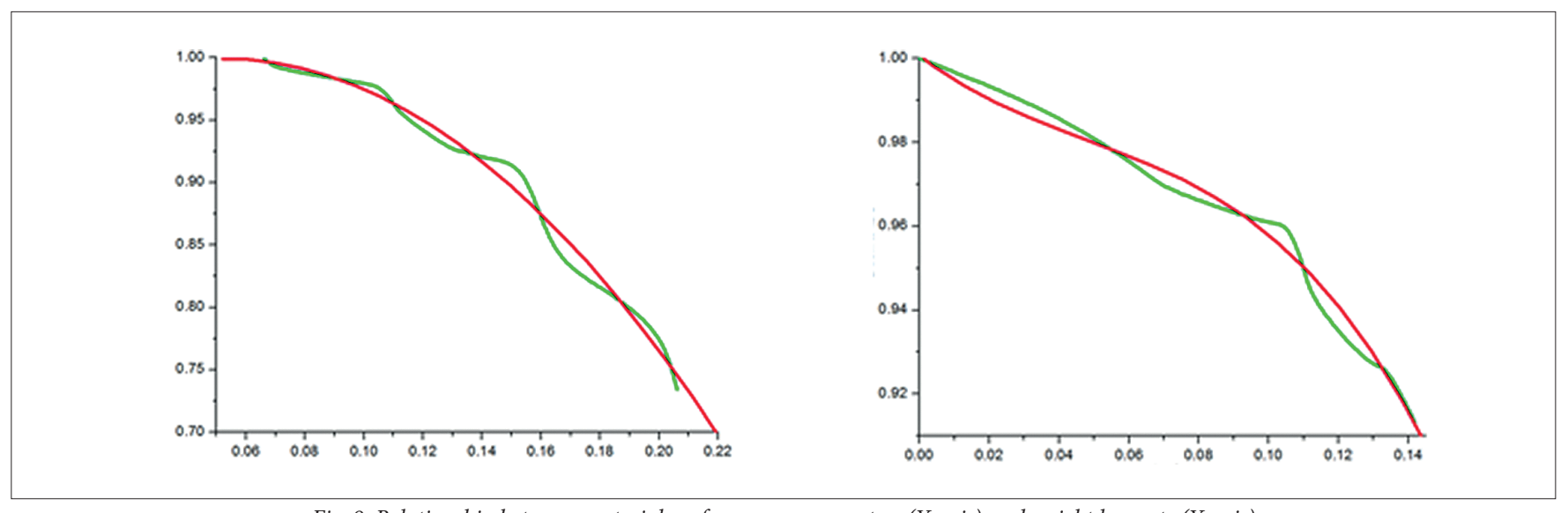

Fig. 9. Relationship between material performance parameters ( $Y$ axis) and weight loss rate (Y axis)
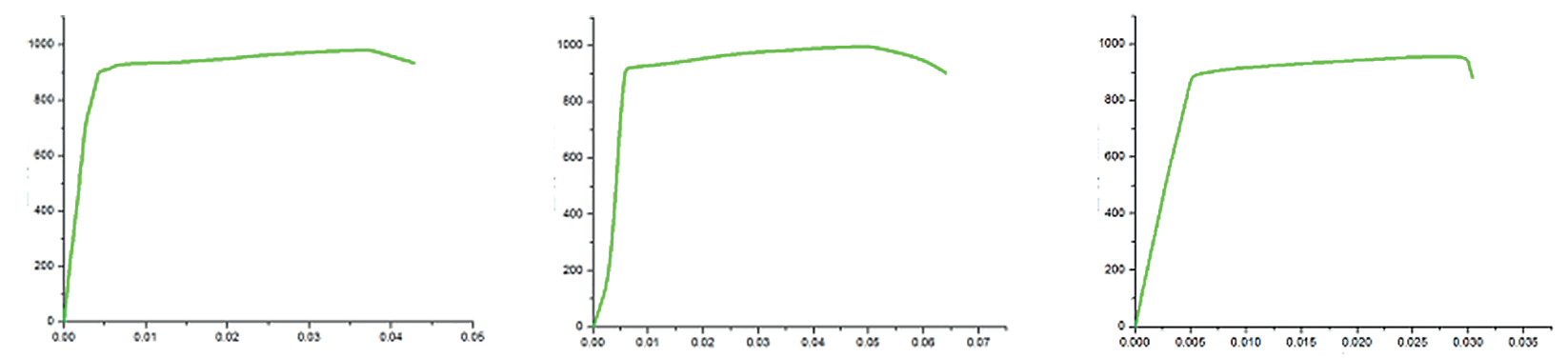

Fig. 10. Stress (X axis)-strain ( $Y$ axis) curve of the casing materials

\section{THE CORROSIVE MATERIAL PERFORMANCE MODEL}

Due to the degree of corrosion, the mechanical properties of the inner and outer walls of the casing may differ. Samples from the inner, the outer, and the whole casing were taken. Then, tensile experiments were performed. The outer, whole, and inner stress-strain curves are described in turn in Fig. 10, and the morphology of the specimen after fracture is shown in Fig. 11.

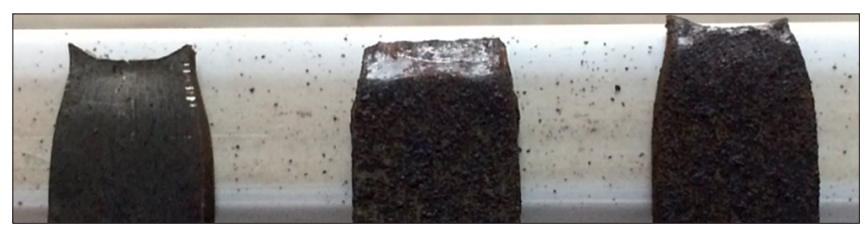

Fig. 11. Fracture of the tensile test pieces

As shown in Fig. 11, the whole, the inner and outer layered tensile test pieces were observed. It can be found from the fracture that the fracture of the intermediate tensile test piece was flattened, while the tensile test pieces layered on the left and right of Fig. 11 were close to flush.

Metallographic inspection was carried out for inner side and outer side, and the results are shown in Tables 7 and 8.

It was very difficult to sample the corroded test pieces, so the number of test pieces in this paper does not meet the standards of the tensile experiment, and the results can only be used as a reference for modeling. Although the inner wall was more corroded than the outer wall, there were many cases where the outer wall was corroded more seriously than the inner wall or the two were almost the same. Therefore, the modeling calculations in this paper were based on sampling, but the method of establishing the model can be used in any case, that is, different corrosive material models can be used to reflect different corrosion characteristics.

Tab. 7. Casing inner side metallographic analysis

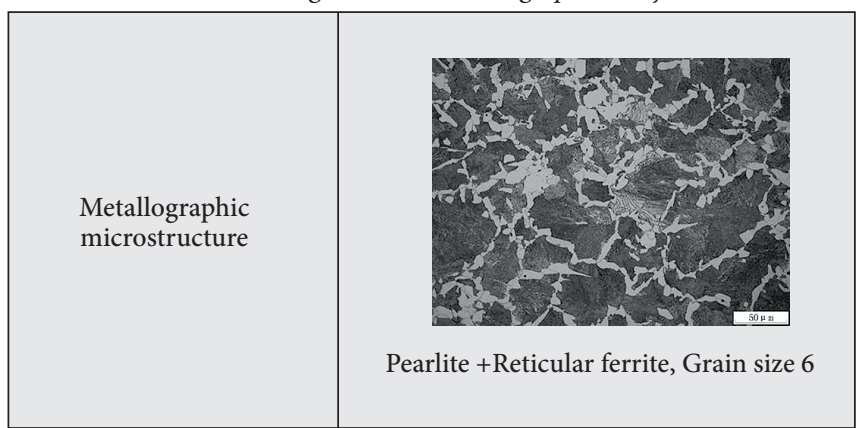

Tab. 8. Casing outer side metallographic analysis

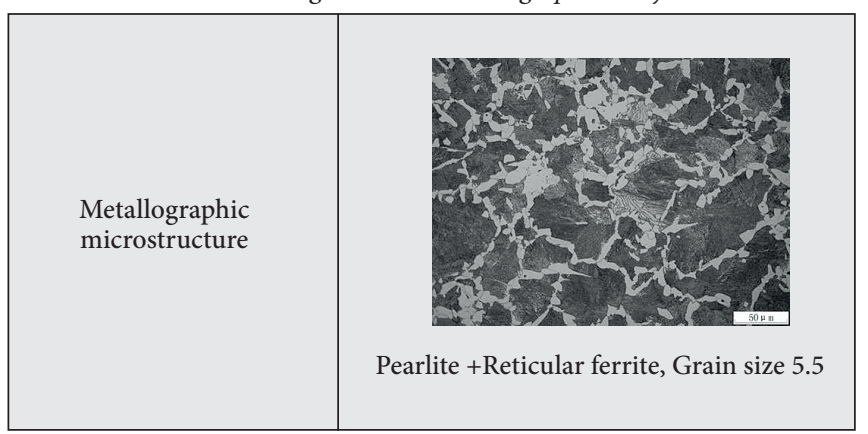




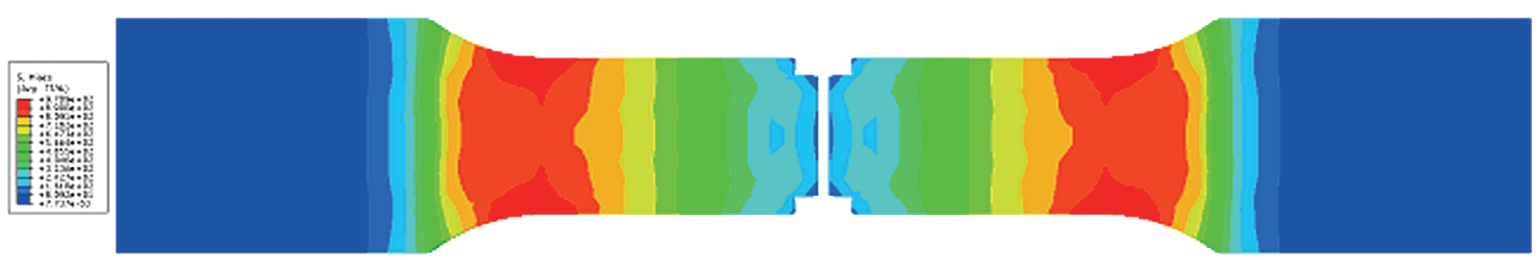

Fig. 12. Tensile experiment simulation

Tensile fractures were simulated using ABAQUS on the above three tensile test pieces prior to the modeling of the casing. In the model, the test piece was divided into two layers, one layer imparting material properties to the inner wall and the other layer imparting material properties to the outer wall $[14,15]$. The parameters are shown in Fig. 12, and the results of the simulation are shown in Fig. 12.

The simulation results show that the stress at break of the test piece was between the tensile strength of the inner wall and the outer wall in the tensile experiment, which was close to the tensile strength of the material when the whole test piece was stretched. It can be seen that for the corrosive material model, the hierarchical setting method proposed in this paper was feasible. Taking the casing analyzed in this paper as an example, a model that gradually weakens the mechanical properties from the outside to the inside was established. The model establishment scheme is shown in Fig. 13.

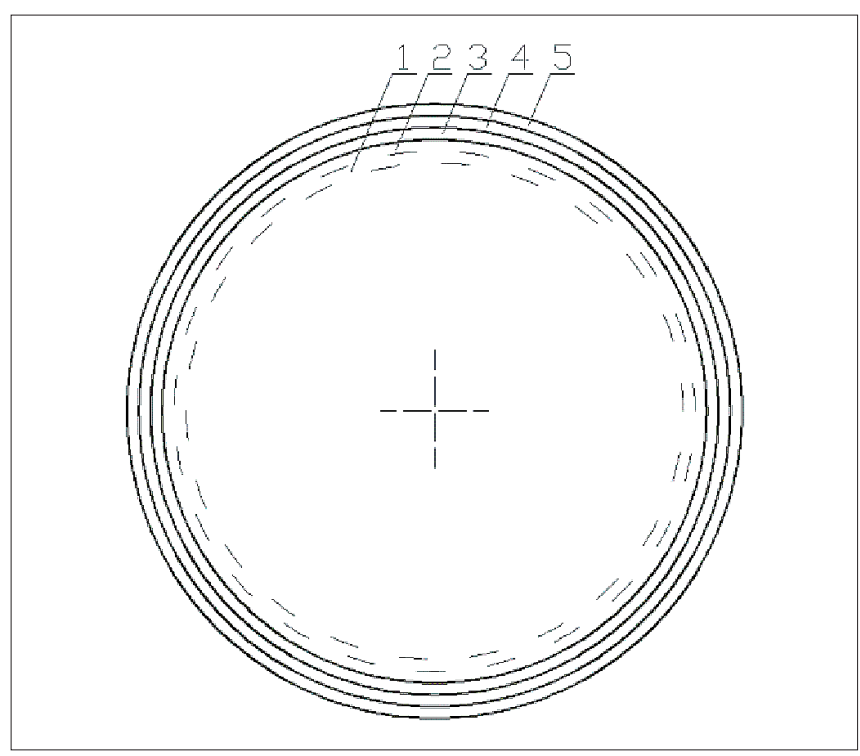

Fig. 13. Establishing scheme for linear weakening model of casing
In the model shown in Fig. 13, the first layer and the second layer indicated by broken lines were portions which have been etched; the third, fourth and fifth layers indicated by solid lines were etched casing. The general principle of material parameter setting is layer $3<$ layer $4<$ layer 5 . The properties of the fourth layer are consistent with that of the second layer, and the properties of the fifth layer are consistent with that of the first layer. The inner wall was defined as the first layer, and its specific expression is:

$$
A_{i+j}= \begin{cases}A_{i-j} & i \geq j \\ A_{1} & i<j\end{cases}
$$

where $A$ is the material parameters, $A_{1}$ is the first layer of the casing inner wall before corrosion, $i$ is the first layer of the casing inner wall after corrosion, and $j$ is the number of layers.

In Eq. (1), the following relationship needs to be satisfied

$$
i \geq h / \delta
$$

where $h$ is the original wall thickness of the casing, and $\delta$ is the maximum wall thickness of each layer.

The model in Fig. 17 was refined according to Eqs. (1) and (2). The tensile test piece model was divided into three layers by using the obtained experimental data. The calculation results are shown in Fig. 14.

It was found that the maximum stress was closer to the tensile strength of the tensile test piece than that of Fig. 14 when the test piece was broken, which further proves the validity of the corrosive material model proposed in this paper.

\section{CONCLUSION}

In this paper, the casing of ocean oil and gas wells was taken as the object, the corrosive fluid in the complex environment of deep-sea drilling was proportioned, and the temperature

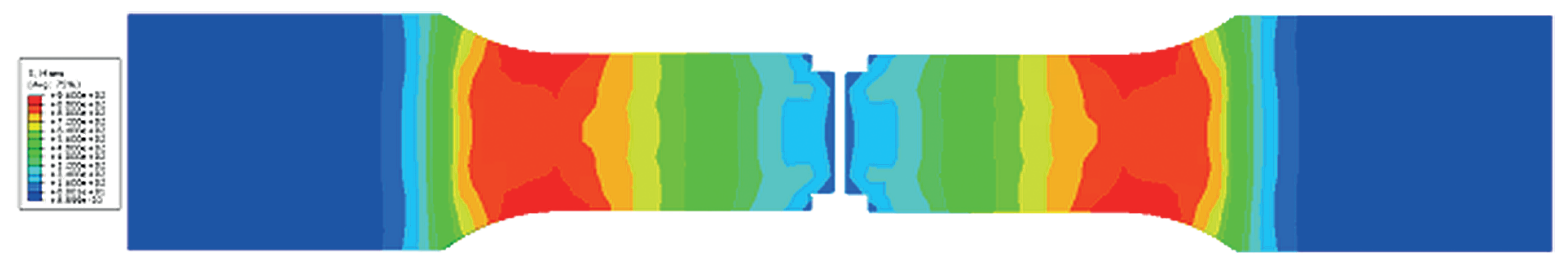

Fig. 14. Model verification 
and pressure were set according to the deep-sea drilling environment. The corrosion experiment, tensile experiment and finite element analysis were carried out on P110 material, and the following conclusions were obtained:

(1) When the weight loss rate of P110 material was less than $15 \%$ after corrosion, the equivalent yield strength and the equivalent tensile strength decrease with the increase of the weight loss rate. When the weight loss rate of P110 material was greater than $15 \%$, the reduction rate of equivalent yield strength increases, while the reduction rate of equivalent tensile strength tends to be flat.

(2) When the weight loss rate of P110 material was greater than $20 \%$, the equivalent yield strength of the material was less than $758 \mathrm{MPa}$, which does not meet the requirements for the use of the $\mathrm{P} 110$ material.

(3) Equations for the yield strength and tensile strength of the P110 material during corrosion are obtained.

(4) A method of establishing a performance model of corrosive material was proposed. The performance model of P110 corrosive material was established according to this method.

\section{ACKNOWLEDGMENTS}

This work reported in this paper was supported by the Sichuan Science and Technology Program (2017TD0023); Project of Sichuan Provincial Department of Education, Robot and Intelligent Equipment Research and Innovation Team of Sichuan Universities (15TD0016).

\section{REFERENCES}

1. Zhao Y., Ding W., Zhang Z., Xu, Y. (2015): Research on the tubing string integrity under complex well conditions and product development. Baosteel Technology, 33(1), 66-71.

2. Shi, X., Chen P., Xu J., Jiang, Z., Nie, R., Qing, X., Zhao, D., Wang, D. (2006): Analysis on residual strength of $\mathrm{CO}_{2}$ tubercular corrosion for casings of oil/gas wells. Natural Gas Industry, 26(2), 95-97.

3. Xu, Z., Yan, X., Yang, X. (2014): Strength time varying analysis of casing with $\mathrm{CO}_{2}$ corrosion defects. Journal of Mechanical Engineering, 50(1), 169-177.

4. Zhu, X-H.., Gao, Y., Jia, Y.-J. (2012): The parameter sensitivity analysis of buttress casing connecting thread under action of bending loading. Engineering Mechanics, 29(10), 301-307.

5. Zhu, X.-H., Dong, L., Tong, H., Gao, Y., Pang, R. (2013): Mechanical behaviors of short-round thread of the API casing under combined load of stretching and bending moment. Acta Petrolei Sinica, 34(1), 157-163.

6. Zhu, X.-H., Zhang, Z., Chang, X, Li, L. (2015): Threedimensional mechanical behavior of worn casing connecting thread in complex structural well. Acta Petrolei Sinica, 36(6), 748-753.

7. Wu, L., Chen, P., Zhu, X.-H., Zhang, W., Jia, Y., Li, J. (2012) Contrast of fatigue failure cycles of drill string during gas drilling. Petroleum Drilling Techniques, 40(1), 42-46.

8. Filippov, A., Mack, R., Cook, L., York, P., Ring, L., McCoy, T. (1999): Expandable Tubular Solutions. Society of Petroleum Engineers, SPE-56500-MS.

9. Chen, S.-J., An, Q., Zhang, Y., Gao, L.-X., Li, Q. (2010): Loading analysis on the thread teeth in cylindrical pipe thread connection. Journal of Pressure Vessel Technology, 132(3), 031202.

10. Chen S.-J., An, Q., Zhang, Y., Li, Q. (2011): Research on the calculation method of tightening torque on P-110S threaded connections. Journal of Pressure Vessel Technology, 133(5), 051207.

11. Cong, Y. (2015): Finite element analysis of casing strength with crack defects. Journal of Shengli College China University of Petroleum, 29(2), 25-27.

12. Li, Y., Deng. J., Wei, B., Tan, Q., Yan, W., Dong, G. (2012): Research on the stress concentration effect of global corrosion cavity of casing inner wall. China Petroleum Machinery, 40(9), 79-77.

13. Wang, C., Wang, S., Xu, S. (2017): Effect of forming temperature on strength of monohole expandable tubular with thread connection. Journal of Plasticity Engineering, 24(3), 50-56.

14. Wang, Y., Ai, Z., Shi, C., Ai, Y. (2017): Study on contact between double metal composite and pipe power slip for offshore well. Polish Maritime Research, 24, 66-73.

15. Zhu, X.-H., Wang, Y., Tong, H. (2013): The parameter sensibility analysis for fishing box tap based on the overall process of elastoplasticity in oil and gas wells. Mathematical and Computer Modelling, 58(7-8), 1540-1547. 


\title{
CONTACT WITH THE AUTHORS
}

Yao Zilin

e-mail:23578993@qq.com

College of Chemistry and Chemical Engineering

Southwest Petroleum University

8 Xindu Avenue, Xindu District

610000 Chengdu City, Sichuan Province

China

\author{
Wang Yu \\ e-mail:xhwangyu@yeah.net
}

Robotics Research Center

School of Mechanical Engineering, Xihua University

9999 Hongguang Avenue, Pidu District,

611730 Chengdu City, Sichuan Province

CHINA

$$
\begin{gathered}
\text { Yang Xuefeng } \\
\text { e-mail: 2781493209@qq.com }
\end{gathered}
$$

Heavy oil development company of PetroChina Xinjiang Oilfield Company 40 Xinyue Road, 834000 Kelamayi City

Xinjiang Province

China

\section{Gao Anping}

e-mail:250815479@qq.com

Wuxi China Resources Gas Co., Ltd, 393 Jinshidong Road, 214000 Wuxi City Jiangsu Province

\section{China}

\author{
Zhang Rong \\ e-mail:253297549@qq.com
}

Petroleum Engineering School

Southwest Petroleum University

8 Xindu Avenue, Xindu District 610000 Chengdu City, Sichuan Province

China

\author{
Jia Yanjie \\ e-mail: jiayj007@163.com
}

Petrochina Southwest Pipeline Company 6 Yingbin Road, 610000 Chengdu City

Sichuan Province

\section{China}

